\title{
A NARRATIVA IMPRESSIONISTA DO ESCRITOR MACHADO DE ASSIS E ATITUDE EXPRESSIONISTA DO DIRETOR LUIZ FERNANDO CARVALHO
}

\section{THE IMPRESSIONIST NARRATIVE OF THE WRITER MACHADO DE ASSIS AND THE EXPRESSIONIST ATTITUDE OF THE FILM DIRECTOR LUIZ FERNANDO CARVALHO}

\author{
Cristiane Passafaro Guzzi ${ }^{1}$ \\ UNESP - Universidade Estadual Paulista (FCLAr) \\ CAPES
}

\begin{abstract}
RESUMO: Enquanto leitor da narrativa impressionista do escritor Machado de Assis, o diretor Luiz Fernando Carvalho, ao transpor o romance Dom Casmurro (1899) para o suporte televisivo, realizando a minissérie Capitu (2008) -, procurou manter a imprecisão no narrar, a exploração sinestésica e sugestiva no contar, mas, ao lançar seu ponto de vista sobre o processo estético de sua realização, explorou carregar no traço, deformando, estilizadamente, as personagens de modo grotesco, caricaturesco, muito mais próximo de uma atitude dita expressionista do que impressionista. Assim, ao procurarmos demonstrar, com este trabalho, a opção feita pelo diretor por uma atitude expressionista na caracterização do narrador sincrético, como exemplo, inferimos uma destruição na realidade convencional dos meios mobilizados e um certo efeito de estranhamento produzido com as elucubrações quase ensandecidas de um narrador que quase cola-se na câmera, interage dentro da própria cena ocorrida em um passado longínquo e, progressivamente, fala por todos os cantos, dentro de um espaço sombrio, permeado de sombras, figurativizando, assim, a própria fantasmagoria de eu interior atormentado. Enfatiza-se, assim, o exagero da condição humana, pelo viés expressionista, engendrando uma potencialidade transfiguradora do pensar, do agir, do estar/ser no mundo. Verificase, portanto, que o grotesco, trabalhado enquanto solução formal para hiperbolizar tal atitude expressionista, figura-se desde a maquiagem até o posicionar-se em cena, permitindo-nos ampliar e engendrar outras possibilidades de leitura para uma obra já tão estudada, mas, constantemente, retomada por sua plurissignificação e por sua atualidade.
\end{abstract}

PALAVRAS-CHAVE: Narrativa Impressionista; Machado de Assis; Atitude Expressionista; Luiz Fernando Carvalho.

ABSTRACT: As a reader of the impressionist narrative of the author Machado de Assis, the director Luiz Fernando Carvalho, when adapting the novel Dom Casmurro (1899) to the television mini-series Capitu (2008), sought to keep the imprecision in the narration, and the synesthetic and suggestive exploration in the telling. But, when working on the aesthetic process of his adaptation, he decided to deeply explore the feature of the characters in a deforming, stylized, grotesque and caricatured way, that was much closer to an attitude considered expressionist than impressionist. Thus, as the aim of this paper is to demonstrate the option made by the director towards an expressionist attitude in the

\footnotetext{
1 Doutoranda em Estudos Literários. UNESP - Universidade Estadual Paulista Júlio de Mesquita Filho Faculdade de Ciências e Letras - Pós-graduação em Estudos Literários. Araraquara - SP - Brasil. 14800-901 crisguzzi@gmail.com
} 
characterization of a syncretic narrator, as an example, we infer that there is the destruction of the conventional reality of the means he used and the creation of a certain effect of strangeness produced by the almost insane lucubrations of the narrator. He almost glues himself to the camera, interacts with the scene that happened in a distant past. Progressively, the narrator speaks in every corner, inside a dark space, permeated by shadows, creating, in this way, the phantasmagoria of a tormented inner self. Thus, the exaggeration of the human condition is emphasized by the expressionist point of view, engendering a transfiguring potential of thinking, acting and being in the world. Therefore, it seems that the grotesque, used as a formal solution to hyperbolize such expressionist attitude, is present from the make-up to the positioning in the scene, allowing us to amplify and engender other possibilities for reading this already much studied literary work, but that is constantly revisited because of its polysemy and contemporariness.

KEYWORDS: Impressionist Narrative; Machado de Assis; Expressionista Atitude; Luiz Fernando Carvalho.

A minha tentativa foi toda esta, a de deixar a "fantasmagoria" da minha Capitu, a "fantasmagoria" do meu Dom Casmurro, num ponto tal capaz de dialogar com a imaginação do espectador. [...] todos esses personagens pertencem a um mundo fabulesco, e precisam permanecer por lá, só assim poderemos dialogar com eles, olhá-los, encontrá-los, para, depois, devolvêlos à Literatura. Esse mundo, porém, é narrado por um homem chamado Dom Casmurro, que no meu modo de sentir está doente, é um doente imaginário, como diria Molière, um doente da imaginação. Talvez pelas circunstâncias da vida dele, talvez pela sua natureza intransponível, ele tenha um olhar transfigurado, quer juntar as duas pontas de sua vida, mas não consegue mais. Não consegue porque ele está trabalhando também sob a idéia do trágico, e a idéia do trágico está ligada à idéia do tempo, tempo que passou e que você não consegue expressar mais, porque já passou.

Luiz Fernando Carvalho, "Diálogo com o diretor""

O romance Dom Casmurro (1899) institui-se como uma obra que convoca leituras em continuidade, permitindo ao leitor que se proponha analisar os significados engendrados pelo texto, a partir da autonomia de seus significantes. Cada leitura da obra do escritor Machado de Assis considera e redimensiona as leituras anteriores, construindo um paradigma crítico que aponta para novas possibilidades de leituras combinatórias.

A minissérie televisiva Capitu (2008) escrita por Euclydes Marinho, com colaboração de Daniel Piza, Luís Alberto de Abreu e Edna Palatnik, e texto final do diretor Luiz Fernando Carvalho, apresenta-se como uma transposição aproximada da referida obra Dom Casmurro, preservando, quase que na íntegra, o conteúdo do romance. Para Luiz Fernando Carvalho, a ideia do conceito de adaptação, em qualquer texto, é um achatamento da obra, um assassinato do texto original, preferindo, portanto, o termo "aproximação", no qual as imagens dominam a cena em detrimento do universo dramático do romance. O texto da minissérie Capitu aparentemente se resolve em uma síntese que destaca trechos literais dos capítulos curtos do livro, citados nos títulos que subdividem cada episódio da minissérie. Estão preservados não só as palavras e os diálogos, como também as diversas camadas do

\footnotetext{
${ }^{2}$ CARVALHO, L.F. Diálogo com o diretor. In: Capitu. Minissérie de Luiz Fernando Carvalho; escrita por Euclydes Marinho; colaboração Daniel Piza, Luís Alberto de Abreu e Edna Palatnik; fotografias de Renato Rocha Miranda e Guilherme Maia. Rio de Janeiro: Casa da Palavra, 2008.
} 
texto, ou seja, essas divisões em pequenos capítulos, através da inserção de planos-sequências com cortes, e que anunciam a cena que está por vir.

As experiências de Machado de Assis enquanto poeta, crítico, contista, dramaturgo e romancista parecem reverberar em seus textos, ao longo de toda sua obra, fornecendo para seus leitores subsídios teóricos, inclusive, de análise para seus próprios trabalhos. E foi nesse movimento, com essas próprias marcas deixadas no texto pelo escritor, que Luiz Fernando Carvalho parece ter encontrado suporte para a realização da minissérie Capitu, conciliado com seu singular modo reflexivo de demonstrar as coordenadas de um fazer visual.

Todo processo estético, seja ele verbal ou sincrético, deve pressupor um olhar de fora do seu realizador. Um eu posicionado do lado de fora em relação ao outro o que possibilita o objeto ser enformado de modo estético. A compreensão que Carvalho faz, seja da crítica tradicional, seja das leituras feitas diretamente sobre a obra por autores escolhidos, transparece nos ressoos figurativos que ele tão bem trabalha por intermédio dos procedimentos de citação, seja de forma direta, seja de forma indireta. Esse ressoo de traços de significação, e que nos remetem aos diálogos com tais textos, configura-se desde a escolha do cenário, o posicionamento da iluminação, os efeitos de enquadramento da câmera, a caracterização e o vestuário das personagens, até a trilha sonora escolhida para embalar certos momentos da trama.

Há uma tomada de posição do diretor em sua recriação artística ao recuperar, mesclar e, ao mesmo tempo, atualizar os valores mobilizados tanto do tempo histórico do romance de Machado, século XIX, como do tempo de sua transposição, século XXI. A confluência de valores, saberes, vozes e técnicas na minissérie produzem um efeito outro de leitura e interpretação para uma obra tão conhecida, mas que ainda permite o reconhecimento de diversas outras vozes presentes em sua enunciação e por procedimentos diversos. Carvalho, ao realizar uma enunciação sobre outra enunciação, parece jogar, inclusive, com as possibilidades existentes de citação do romance dentro, agora, de um outro suporte; permitindo, assim, que o dialogismo presente no processo mostre-se, inclusive, de modo escancarado.

Enquanto leitura singular, Capitu trabalha o conteúdo do romance tentando preservar os diálogos, as personagens, as ações, deslocando, quase sempre, na expressão ${ }^{3}$ os diferentes sentidos atribuídos pela trama. O primeiro tratamento dado ao próprio texto de Machado não veio somente do olhar de Carvalho, mas de Euclides Marinho, seu colaborador na realização da minissérie, que produziu para o diretor um enorme levantamento dos trechos mais importantes da narrativa, criando determinadas ligações que guiavam a trama sem prejuízo em sua sequência. Sobre essa possibilidade de uma transposição "fiel" do conteúdo, Carvalho (2008, p. 77-78) afirma que

[...] o texto usado pelo elenco é absolutamente fiel ao que foi produzido por Machado. Fiz questão de ser bastante rigoroso neste ponto. O texto é Machado puro. Sem nenhum artigo meu, sem nenhuma vírgula minha. [...] O que eu fiz foi reafirmar o Machado em termos de conteúdo e linguagem. A síntese do texto é dele. É claro que eu espelhei aquelas situações e as lancei

\footnotetext{
${ }^{3}$ Quando se afirma, aqui, uma maior exploração evidente na expressão, não se está afirmando uma dissociação de seu conteúdo, pelo contrário. É somente por intermédio dele que conseguimos trabalhar com essas verificações com um texto que envolve diversas outras linguagens, destacando-se a visual.
} 
em outras relações de imagens, procurando um diálogo com possibilidades simbólicas da modernidade, abrindo o texto a outras visibilidades.

O que fica claro, para nós, no processo de transposição realizado na minissérie, é que Carvalho contou com a "ajuda", além da memória discursiva construída pelo leitor - que reconhece a presença do romance machadiano quase em sua íntegra pelos diálogos mantidos-, mas, também, dos procedimentos de citação e referência, os quais permitiram, por sua vez, o "controle" e o próprio escancaramento dessas nossas intuições.

O plano da narrativa de Dom Casmurro ancora-nos em um ambiente permeado por uma atmosfera que figurativiza um estado psíquico dramatizado por múltiplos devaneios, sensações e impressões. Há uma inquietude predominante em todo o cenário que constitui a história, seja pela figura ensandecida do narrador, seja pelos volteios da própria narrativa que se configura de modo desnorteado, atormentado, repetitivo e, muitas vezes, desconexos da situação anteriormente prescrita.

A falta de paciência que contempla o narrador Casmurro contribui para o desenrolar de uma narrativa convulsa, que se estrutura por intermédio de digressões e comentários, caracterizando tal narrador como um notável tagarela que precisa, a todo momento, e compulsivamente, falar sobre tudo o que pensa e o que não pensa, mesmo que seu comentário possa não fazer sentido naquele momento da trama. Esse falar de si, que tenta recuperar algum entendimento sobre a constituição da própria identidade, estrutura e enquadra a narrativa dentro de um grande ensaio sobre o falar reflexivo desse narrador de "crença volúvel", conforme classifica o crítico Schwarz (1990).

$\mathrm{O}$ gênero ensaio pode ser aproximado do conto por tramar ideias e por apresentar uma brevidade necessária. No caso do romance machadiano, que se mostra estruturado de modo ensaístico ou permeado de pequenos fragmentos de reflexões, podemos pensar que há, entre os gêneros citados, migrações das características que os definem, mas, cada um, dentro dos limites convencionados e, notoriamente, explorados. Além disso, os ensaios conseguem, muitas vezes, relatar fatos muito próximos à maneira ficcional de se contar uma história, permitindo-nos, assim, aproximá-los também ao gênero do romance.

Edgar Allan Poe (2004, p.190), em suas resenhas sobre o escritor Nathaniel Hawthorne, ensina-nos que os ensaios são pequenas pausas, reflexões, medidas de pesar, de ponderar, espaços para pequenos devaneios. Com o ensaio, não há trama propriamente instalada, e sim uma abertura para sua suspensão, um repouso para vir à tona um devaneio. Ao ensaiar um pensamento, procura-se provar, comprovar, trabalhar com as experiências vividas e não vividas para atestar a veracidade e confiabilidade do que foi declarado de modo ensaístico. Desse mesmo modo, o que vemos na história de Dom Casmurro é um contar de experiências e a falta delas, refletindo, sob um viés ensaístico em ação, a confissão de um narrador que quer falar de si para, quem sabe, expurgar os sentimentos e as memórias tão nebulosas que perpassam sua mente já cansada e fatigada pela própria idade.

Uma narrativa que se apresenta como de atmosfera é elíptica por natureza, uma vez que esta só cresce, adensa-se, por intermédio dos interditos que são espraiados ao longo do relato. Na história de Dom Casmurro não há trama propriamente dita. Há impressões, recordações, volteios e tentativas de recuperação, pela memória de um narrador já envelhecido e afetado pelos ciúmes de sua companheira de vida, Capitu, do que "foi e poderia ter sido" em vida.

O plano de narrativa ambiente de Dom Casmurro figurativiza um estado psíquico do narrador-personagem, dramatizando seus múltiplos ensaios, devaneios e sensações. Há, em todo o contar reflexivo, pequenas pausas narrativas, instantes de repouso 
no falar progressivo, trabalhados por intermédio do recurso da analepse (flashback) e da prolepse (flashforward) ${ }^{4}$, que apresentam como efeitos de sentido a interrupção no curso cronológico da narrativa para a apresentação de eventos que aconteceram anterior ou posteriormente na narrativa. Nesse sentido, a minissérie, com os recursos disponíveis pela tecnologia de filmagem, enquandramento e montagem, evidencia tais anacronias no modo como apresenta as personagens da história. Estas são anunciadas por vinhetas de abertura que se inserem por uma voz, em off, mas dotada por tom caricatural, ao estilo de locutores antigos de rádio que narravam, diariamente, os romances-folhetins que circularam nos séculos XVIII e XIX.

A manutenção dos títulos, como no romance, a cada plano-sequência equivalente aos capítulos transpostos, anuncia, como uma espécie de corte, as cenas que estão por vir do romance e que se apresentam, muitas vezes, interpoladas, como "narrativas secundárias", na terminologia de Gérard Genette (1972), ou narrativas de "encaixe", na terminologia de Tzvetan Todorov (1970). Ainda que secundárias ou encaixadas, essas narrativas, ao longo de toda a história, vão constituindo-se como informações necessárias para o entendimento do todo. Na minissérie, esses capítulos explicativos e funcionais, quase que como resumos explicativos das personagens e suas ações, são reforçados pelos cortes dos planos, denotando uma espécie de truncamento no desenrolar do enredo e do ritmo de filmagem, estabelecendo, como consequência, um tempo prolongado na história contada/filmada.
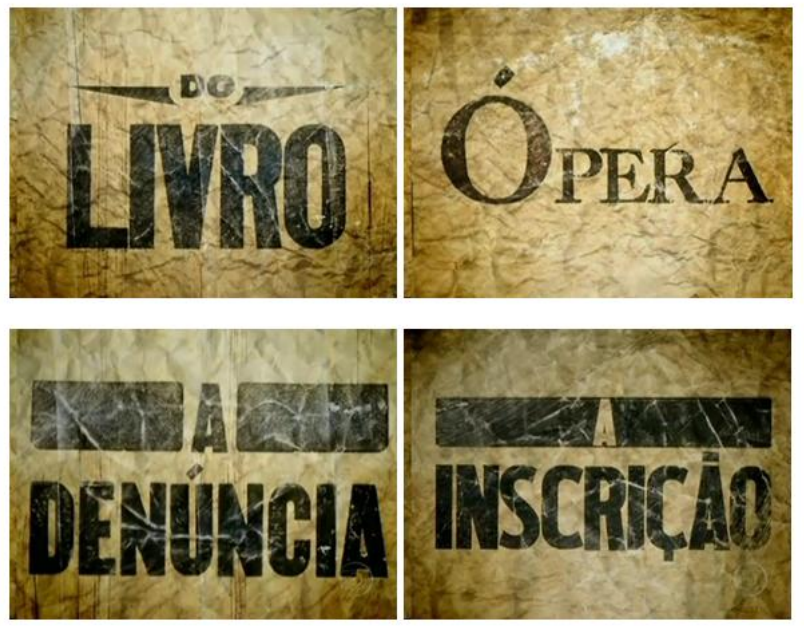

Figura 1 - Cartelas/Vinhetas de abertura dos capítulos/episódios

O cinema funda-se como uma narrativa dilatada. Eleva-se à abertura de histórias ao extremo, por apresentar uma porosidade narrativa que permite maior exploração do procedimento discursivo da intertextualidade e da interdiscursividade. Por ter um princípio aberto de composição e por atuar com uma plasticidade manipulável, a linguagem cinematográfica dilata sua narratividade. Já o gênero televisivo seriado, por depender de ganchos necessários para a compreensão da totalidade da história pelos seus telespectadores, mostra-se, por sua vez, mais voltado para uma tentativa didática de exposição quase lúdica do

\footnotetext{
${ }^{4}$ De acordo com as contribuições de Gerárd Genette, em seu livro Discurso da narrativa (1972).
} 
que aconteceu, do que vai acontecer e do que poderia ter acontecido. $\mathrm{O}$ espaço narrativo da televisão necessita de um enredo propriamente dito, uma vez que sugestões, impressões e circularidades não avançam o relato e, em consequência, não traduzem um produto pronto de história que deve servir aos interesses daqueles que assistem ao gênero para, quase sempre, entretenimento ou lazer.

Contudo, o trabalho televisivo que vem sendo consolidado pelo diretor Luiz Fernando Carvalho parece romper com essa hegemonia de feitura televisiva comercial, quando este se assemelha e se apropria da linguagem cinematográfica e de suas potencialidades dentro da esfera de produção da televisão. Há um princípio aberto de composição em suas obras que permitem a exploração dessas porosidades narrativas e dos repertórios mobilizados para a transposição de romances literários, com toda carga de tradição retomável e manipulável dentro do enredo, agora, televisivo.

As retomadas necessárias para garantir a fidúcia do enunciatário ao narrado configuram-se por intermédio de estratégias manipuláveis e variáveis, como, por exemplo, pela exploração da musicalidade que finda um relato e anuncia, por outra melodia, uma dada história ou outra continuidade. Além disso, temos o trabalho da montagem que produz uma significação de alternância de planos, a partir do ponto de vista de quem recorta, seleciona e combina o que será filmado, que anuncia e prepara o telespectador para um final, uma parada ou, até mesmo, uma continuidade na ação plasmada em tela.

Em Capitu, especificamente, temos um trabalho de abertura narrativa, análoga à narrativa do cinema, quando verificamos que o trabalho do diretor, mais do que uma transposição do conteúdo e da expressão do romance para outro suporte, faz uma retomada e uma exploração dos ressoos das leituras que transitam em torno do romance, do escritor e, também, de seu próprio repertório de leitura enquanto leitor anunciado de Machado e tantos outros. Assim, há uma manipulação dos conteúdos mobilizados para a constituição desse trabalho realizado na televisão e que permite verificar uma confluência com a obra transposta, mas, também, e principalmente, uma certa extrapolação de sentidos já consolidados pelas leituras retomadas e que o diretor, em seu processo de seleção e combinação, permitiu-se engendrar outras possibilidades de sentidos, leituras e entonações.

O romance, como já evidenciamos, trabalha com sensações para um determinado ambiente ancorado em uma atmosfera densa, perturbada, construída sob as sombras que atormentam a mente do narrador. Tal configuração imprime/exprime uma sensação na/da personagem, que evidencia seu interior perturbado por um tempo e por um espaço em ruína. Incorporam-se, durante o relato, gestos insólitos no contar que mexem e reacendem sinestesicamente as múltiplas recordações vividas por Bentinho. Cria-se, portanto, impressões, durante toda a história, as quais são sugeridas, indicadas, mas nunca comprovadas, confirmadas. Temos um contorno, um espécie de esboço de pensamentos soltos, mas não seu preenchimento, sua consolidação.

Há uma desreferencialização de um tempo datado, marcado, de um Rio de Janeiro do século XIX, para criar um efeito de sentido de universalização do tema, da obra. A ênfase dada a um tempo que não pertence mais nem a ele mesmo, uma vez que não volta-se atrás com nada que já foi realizado, possibilita estender sua significação para a consciência de finitude e de transitoriedade das coisas, consolidando, assim, esta atmosfera sombria, mítica, enigmática e trágica que ambienta Bento Santiago.Vale ressaltar, contudo, que apesar de não termos a marcação do tempo cronológico, há, pelo movimento da iluminação utilizada na minissérie, uma separação nítida entre as duas fases do romance retratadas pela minissérie. A primeira, a infância de Bentinho e Capitu, configura-se em tons mais claros, luminosos, de cor branca e sem a interferência de gelatinas artificiais. Já na segunda fase, da maturidade do 
casal, nota-se o predomínio de cores mais intensas, como o preto, o roxo, o azul escuro, construindo uma imagética densa, que figurativiza os estados de ânimo das personagens em fases distintas.
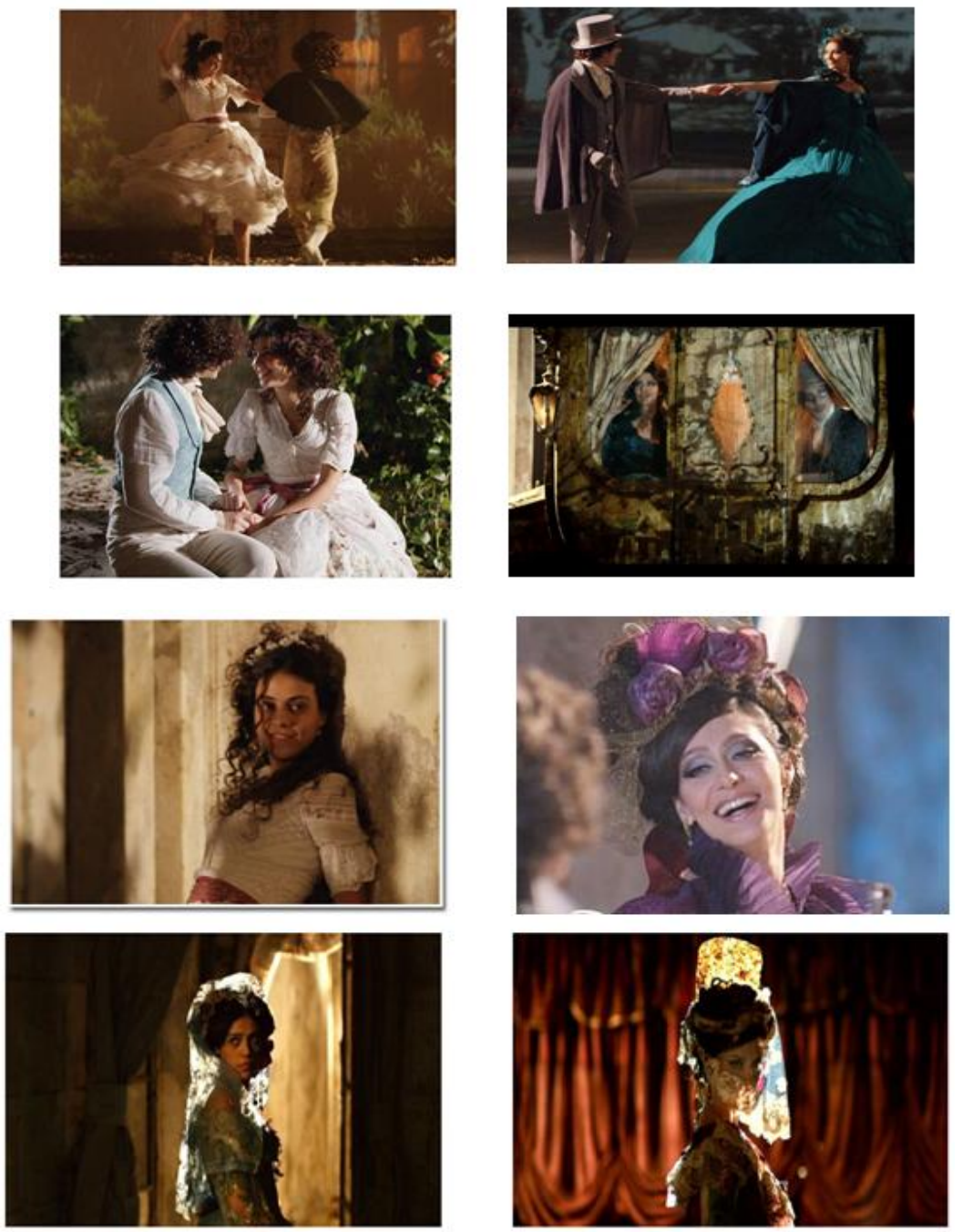

Figura 2 - O contraste entre cores frias e cores quentes

Como temos a história pela câmera do olhar de um narrador, primeiramente ainda não tão afetado pelos ciúmes e pelo rememorar, tal iluminação condiz com um estado de alma aparentemente de tranquilidade. Depois, com a progressão e com a intensidade dos fatos, há, visualmente, pelas cores trabalhadas, a afetação dos ânimos, principalmente, do narrador Dom Casmurro.

O registro da memória como matéria do romance sugere uma ausência de verdade no que é contado, fazendo com que as sensações e impressões sejam responsáveis pelo estabelecimento de um juízo de valor à narrativa. Vale ressaltar que esse juízo mostra-se dúbio, ambíguo e permeável a diversas leituras, uma vez que o que o assegura são as inconstâncias do narrar. Desse modo, a percepção do tempo, o ritmo de memória e um contar existencial por meio de lembranças e impressões filia o romance de Machado ao impressionismo, corrente estilística autônoma, que não se enquadra nem na mentalidade neorromântica do simbolismo, nem nas experiências linguísticas feitas pelas vanguardas 
lideradas por Mallarmé ou Rimbaud, conforme pontuou José Guilherme Merquior, em seu texto "Machado de Assis e a prosa impressionista" (1996).

A prosa impressionista exige uma certa distância, uma calma necessária ao relato, para se prestar atenção nos detalhes espraiados ao longo da história e que, reunidos, podem constituir uma informação, de alguma forma mais precisa, mais concluída, em meio a tanta sensação dispersada. O impressionismo não carrega na emoção, pois se mostra objetivo diante do que se quer representar: uma dada impressão do objeto em destaque, da narrativa, da personagem ou de algo relevante para o entendimento do todo, como elucidado nas paisagens quase descritivas de Monet ou nos retratos precisos das características a serem postas em evidência nos quadros de Van Gogh. Os artistas desta corrente não tentam recriar, ao pé da letra, a natureza e nem tentam fazer reproduções fieis delas. O que buscam é explorar, com pinceladas grossas, o que possa sugerir uma ideia da paisagem ou, no caso do romance, um traço que remeta à caracterização necessária para a consolidação daquela personagem, daquele espaço, daquele tempo. Para o professor e pesquisador Luiz Gonzaga Marchezan, em seu artigo "Metáforas da casa e do mar em Dom Casmurro" (2008, p. 65),

O autor de Dom Casmurro retrata sensações, atmosferas, resultantes, no âmbito da narrativa, do vivido, absorvido e que motivam as sensações deflagradas pelas personagens mediante o que viveram e experimentaram.O criador de Bento Santiago é impressionista, queremos enfatizar. Impressionismo é a expressão indireta de um significado. A impressão é decorrente de um conjunto de fatores ligado ao acontecimento narrado e, por isso, deflagra sensações. As sensações nos dão as disposições, as condições que se associam ao acontecimento narrado e trabalham os efeitos de sentido dessas qualidades sobre nós.

Temos, assim, pelo viés impressionista, um mergulho na narrativa machadiana que se ergue mediante sensações trabalhadas, sugeridas, (im)pressionadas por um narrador obcecado pelo próprio reviver, num tempo e num espaço trabalhados por uma memória afetada e já fragmentada. O subjetivismo decadente que Machado de Assis vem explorando desde Memórias Póstumas de Brás Cubas (1881), Quincas Borba (1891), Esaú e Jacó (1904), Dom Casmurro (1899) e, por último, Memorial de Aires (1908), filia o escritor como um ficcionista impressionista, afastando-o dos naturalistas e seus gostos peculiares por um relato linear e determinista. Sua linguagem, quase sempre conotativa e carregada de metáforas e de metonímias, encontra, na exploração constante da ironia, um engendramento de significados que se constroem não na superfície, mas nas profundidades e nos entrecruzamentos do texto. Portanto, é um estilo de escrita que tende mais para a sugestão do que para a minúcia, à elipse ao invés do esbanjamento verbal, à concisão no lugar do descritivismo, à sutileza, no lugar das obviedades.

Enquanto leitor da narrativa impressionista de Machado, o enunciador sincrético, ao transpor o romance para o suporte televisivo, optou por manter, sim, a imprecisão no narrar, a exploração sinestésica e sugestiva no contar. No entanto, carrega no traço e deforma, estilizadamente, as personagens de modo grotesco, caricaturesco, muito mais próximo de uma atitude dita expressionista do que impressionista. Assim como o escritor Franz Kafka construía seus personagens deformados, isolados num espaço claustrofóbico, desagregados de suas firmezas e perdendo suas próprias referências, o narrador Casmurro da televisão será constituído por uma evidente deformação gradativa que avançará conforme compreenda a falta de identidade e clareza para sua própria vida. 
O grotesco, trabalhado enquanto solução formal para hiperbolizar tal atitude expressionista, figura-se desde a maquiagem até o posicionar-se em cena do protagonista, que, em muitos momentos, mostra-se arredio, instintivo, impulsionado pela deformação interior que o perturba, dilacera. As ações abruptas, violentas, afetadas pelos ciúmes e pelo descontrolar das demais emoções de Casmurro hipertrofiam, analogamente, ao falar de si progressivo, a expressão. Além do mais, ao optar por uma atitude expressionista na caracterização do narrador sincrético, inferimos uma destruição na realidade convencional dos meios mobilizados e certo efeito de estranhamento produzido com as elucubrações ensandecidas de um narrador. Este quase se cola na câmera, interage dentro da própria cena ocorrida em um passado longínquo e, progressivamente, fala por todos os cantos, dentro de um espaço sombrio, permeado de sombras. Assim, figurativiza-se no espaço exterior a própria fantasmagoria de eu interior atormentado.

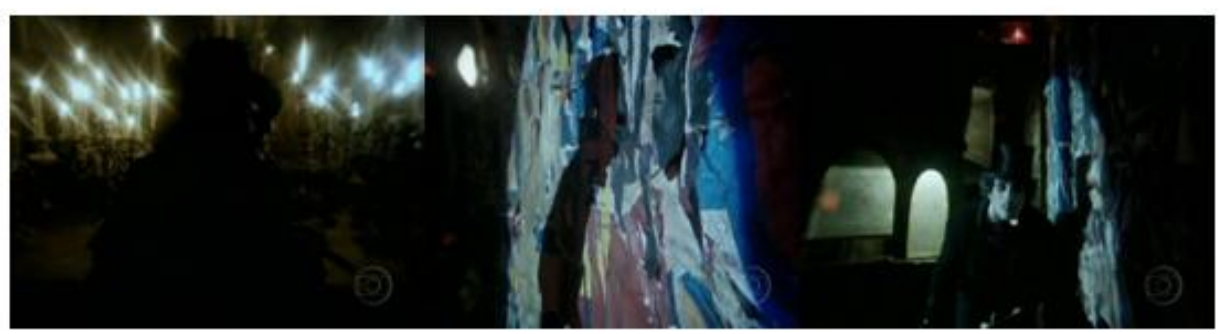

Figura 3 - As sombras e a fantasmagoria de um narrador atormentado

O peso da tragicidade que envolve o tempo psicológico da personagem é enfatizado pelas palavras do próprio diretor $(2008$, p. 78 ) quando este declara sobre a concepção fanstamagórica de suas personagens:

A minha tentativa foi toda esta, a de deixar a "fantasmagoria" da minha Capitu, a "fantasmagoria" do meu Dom Casmurro, num ponto tal capaz de dialogar com a imaginação do espectador. [...] todos esses personagens pertencem a um mundo fabulesco, e precisam permanecer por lá, só assim poderemos dialogar com eles, olhá-los, encontrá-los, para, depois, devolvêlos à Literatura. Esse mundo, porém, é narrado por um homem chamado Dom Casmurro, que no meu modo de sentir está doente, é um doente imaginário, como diria Molière, um doente da imaginação. Talvez pelas circunstâncias da vida dele, talvez pela sua natureza intransponível, ele tenha um olhar transfigurado, quer juntar as duas pontas de sua vida, mas não consegue mais. Não consegue porque ele está trabalhando também sob a idéia do trágico, e a idéia do trágico está ligada à idéia do tempo, tempo que passou e que você não consegue expressar mais, porque já passou.

A ficção que se faz expressionista rompe com a literatura realista, ao recompor simbolicamente os valores preconizados pela nossa cultura ocidental. Machado de Assis, do mesmo modo, conforme já salientamos no capítulo 2, veio romper com a classificação de sua literatura dita como realista, uma vez que não se prendeu a nenhuma tese, trabalhando as tendências realistas nos seus devidos limites, alegando, inclusive, ser o realismo um "[...] messianismo literário [que] não tem a força da universalidade e nem da vitalidade; [trazendo] consigo a decrepitude." (MACHADO apud MARCHEZAN, 2008). Nesse sentido, levantamos a hipótese em nossa leitura de que o enunciador televisivo tenha optado por esse 
deslocamento do viés impressionista a uma atitude expressionista para, então, descolar a imagem realista que predominou no trato com a obra machadiana em sua recepção.

A solução, portanto, por uma configuração discursiva de um narrador que carrega um falar progressivo, reflexivo e decadente, caracterizado por insinuações e ações grotescas, incomuns, incongruentes, formando um personagem atormentado, assombrado por si próprio, formaliza a dramatização necessária para a construção de um tom grandiloquente e exagerado, alcançado pelo diretor, para enfatizar a degradação do narrador e da própria sociedade retratada. É importante destacar que o realismo, portanto, é trabalhado na constituição axiológica das personagens e das reflexões que elas instauram no dizer narrativo e não como simples e mera ilustração dos costumes vigentes em determinada época.

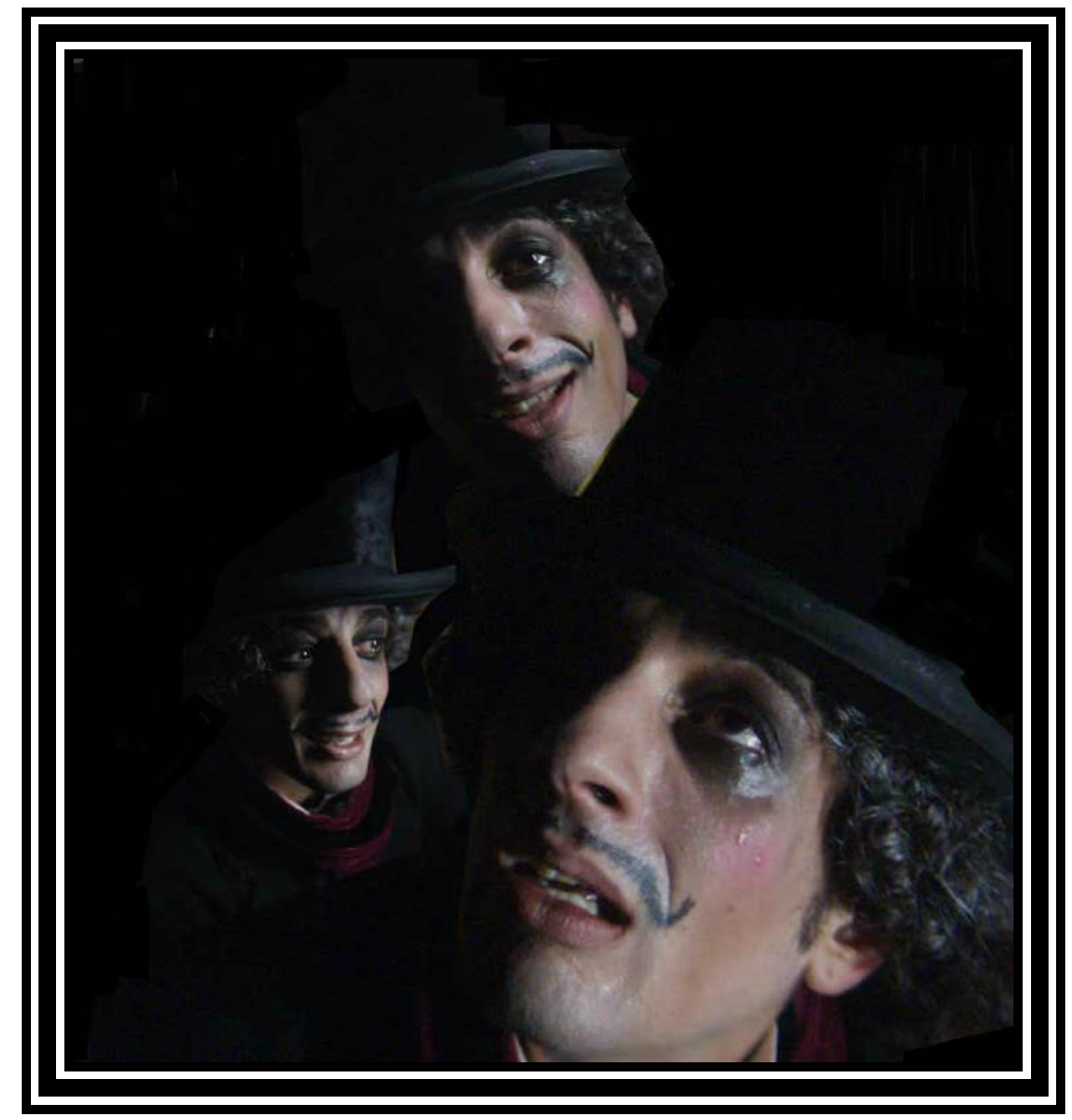

Figura 4 - Tomadas de cenas retiradas da minissérie Capitu

Como podemos observar nas tomadas de cenas, o narrador Casmurro é focalizado com a maquiagem toda borrada, produzindo uma caracterização melancólica, desvairada pelas recordações que o atormentam, dentro de um espaço circuncidado, fechado, como emblematicamente nos ensinou Poe com suas personagens dilaceradas, que figuratiza essa alma presa, enclausurada por seus sentimentos, suas dúvidas, suas próprias ambiguidades construídas pelas lembranças tortuosas de um vivido. 
Pode-se verificar, ainda, o movimento de degradação no andar da personagem que, gradativamente, vai se tornando curvado, cambaleante, conforme o peso das recordações e o avançar no relato narrativo. O expressionismo não se mostra como uma tendência artística, mas, sim, como uma atitude que tende a se metamorfosear. A mudança do narrador faz-se mediante a transformação interna pela qual a personagem passa, ao constatar, segundo suas próprias impressões, o que fez de sua vida e o que poderia ter sido, caso enfrentasse seus fantasmas, seus demônios. O registro pela câmera mostra-se intenso, caótico, desesperado, em determinadas cenas, evidenciando a presença do irracional, do demoníaco e dos impasses presentes no interior da personagem flagrada. Em outro momento da narrativa, contudo, temos o frear de tal ritmo do registro pela câmera, figuratizando, desse modo, o estado apático e melancólico que dominará a personagem de Bento Santiago nas cenas finais. Observamos, assim, um plano de expressão extremamente acelerado, em contrapartida de um conteúdo relativamente desacelerado, uma vez que nada, de fato, acontece em cena, a não ser o curso de seus pensamentos evocados.

Enfatiza-se, assim, o exagero da condição humana, pelo viés expressionista, engendrando uma potencialidade transfiguradora do pensar, do agir, do estar/ser no mundo. $\mathrm{O}$ grotesco, trabalhado enquanto solução formal para hiperbolizar tal atitude expressionista, figura-se desde a maquiagem até o posicionar-se em cena, que, em muitos momentos, mostrase arredio, instintivo, impulsionado pela deformação interior que perturba, dilacera. As ações abruptas, violentas, afetadas pelos ciúmes e pelo descontrolar das demais emoções de Casmurro, hipertrofiam, - analogamente, ao falar de si progressivo -, a expressão, hiperestilizando-a, figurativamente, por intermédio dos recursos mobilizados pela sintaxe visual que apresenta, a seu favor, a musicalidade, o cromatismo, o ângulo cênico, os enquadramentos, os figurinos, os cenários, a gestualidade, contribuindo, assim, para a construção de um todo significante e relacionado.

Mais do que leitor de Machado e de sua crítica, Luiz Fernando Carvalho parece atualizar e deslocar suas leituras, engendrando significações outras, plurais; permitindo, inclusive, que espectadores de imagens prontas, como é o caso do público, em geral, do gênero televisivo, desacostumados a observar as fabulações de um modo geral, comecem a dialogar com o que cada fabulação traz de invenção e estímulo para a imaginação. Dentro do exagero e da hiperbolização que caracterizou a minissérie, encontramos sutilezas que permitem um estudo aprofundado da obra, da crítica, da tradição, e, principalmente, das reverberações que a produção do escritor Machado de Assis até hoje inaugura.

\section{REFERÊNCIAS}

ASSIS, M. de. Obras completas. Rio de Janeiro: Nova Aguilar, 1979. 3 V.

Dom Casmurro. Apresentação de Paulo Franchetti \& notas de Leila Guenther. Cotia: SP; Ateliê Editorial, 2008.

CAPITU. A partir do Romance Dom Casmurro de Machado de Assis. Escrito por Euclydes Marinho. Colaboração Daniel Piza, Edna Palatnik, Luís Alberto de Abreu. Texto Final e Direção Geral. Luiz Fernando Carvalho. Distrito Industrial- Manaus: Sistema Globo de Gravações Audiovisuais LTDA, 2009. 2 DVD'S, widescreen, color.Produzido por Globo Marcas DVD e Som Livre.

CARVALHO, L.F. Capitu. Minissérie de Luiz Fernando Carvalho; escrita por Euclydes Marinho; colaboração Daniel Piza, Luís Alberto de Abreu e Edna Palatnik; fotografias de Renato Rocha Miranda e Guilherme Maia. Rio de Janeiro: Casa da Palavra, 2008. 
CASA, Vol.10 n.2, dezembro de 2012

MARCHEZAN, L. G. As metáforas da casa e do mar em Dom Casmurro. Revista da Anpoll. Vol. 1.24 n $\quad 2008.2$ Disponível em: http://www.anpoll.org.br/revista/index.php/rev/issue/view/1/showToc. Acesso em 12 jun.2012.

MERQUIOR, J. G. Machado de Assis e a prosa impressionista. In: De Anchieta a Euclides: breve história da literatura brasileira I. 3.ed.Rio de Janeiro: Topbooks, 1996.

POE, E. A. Segunda resenha de Edgar Allan Poe sobre Twice-Told Tales, de Nathanael Hawthorne. In: KIEFER, C. A poética do conto. Porto Alegre: Editora Nova Prosa, 2004, p. 189-199.

SCHWARZ, R. Machado de Assis: um mestre na periferia do capitalismo. São Paulo, Duas Cidades, 1998.

Recebido em: 11/08/12

Aprovado em: 08/10/12 